\title{
FAKTOR PENDUKUNG SMART CITY INITIATIVES
}

\author{
Rita Komalasari S.Si., M.Kom. \\ Dosen Program Studi Manajemen Informatika \\ Politeknik LP3I Bandung \\ E-Mail : ritakomalasari123456@gmail.com
}

\begin{abstract}
Abstrak : Pengelolaan kota dengan menjadikan kota menjadi "smart" merupakan penanganan masalah yang timbul akibat pertumbuhan penduduk perkotaan dan urbanisasi yang berjalan cepat. Menyatakan sebuah kota adalah "smart" adalah sebuah konsep yang didasari oleh keterkaitan komponen tiga dimensi utama sebuah kota yaitu, teknologi, masyarakat dan institusi yang berintegrasi dengan infrastruktur dan layanan berbasis teknologi, dan tata kelola bagi peningkatan yang merubah sebuah kota menjadi "smart". Perkembangan teknologi informasi dan komunikasi yang menyebabkan perubahan besar dalam berbagai bidang, termasuk didalamnya munculnya smart city dan kebiasaan penggunaan teknologi dalam kehidupan masyarakat.
\end{abstract}

Kata Kunci : Tata kelola, Smart city, Teknologi Informasi dan komunikasi

\section{Pendahuluan}

Pesatnya pertumbuhan urbanisasi menyebabkan banyak permasalahan yang timbul bagi suatu kota. Kepadatan penduduk yang setiap saat berdatangan menambah jumlah penduduk kota yang menyebabkan kepadatan penduduk. Tidak setiap pendatang yang datang ke kota memiliki tempat tinggal dan pekerjaan yang tetap sehingga mengakibatkan tumbuhnya pemukiman-pemukiman kumuh sepanjang bantaran sungai, yang berakibat pada timbulnya masalah sampah dan limbah masyarakat, kemacetan lalu lintas akibat kemudahan memperoleh kendaraan menyebabkan bertambahnya kendaraan di jalan raya, kerusakan lingkungan akibat ketidaksadaran masyarakat dalam menjaga kebersihan lingkungan dan fasilitas setempat. Pemerintah kota yang tidak sanggup menangani masalah daerahnya akan memicu ketidak percayaan masyarakat terhadap kemampuan pemerintah yang mengakibatkan timbul masalah sosial di masyarakat.

Saat ini, teknologi informasi menyebabkan berbagai perubahan dalam segala aspek sosial dan ekonomi dari kehidupan manusia dan berdampak langsung terhadap masyarakat yang juga merubah dunia dengan cepatnya dari sebuah masyarakat tradisional menjadi masyarakat yang menjalani hidup menggunakan teknologi informasi. Aplikasi dari berbagai teknologi informasi berdampak secara langsung dan tidak langsung terhadap rutinitas kehidupan masyarakat. Fenomena yang menyebar begitu cepat dan secara luas yang mengakibatkan perubahan mendasar dalam budaya, struktur ekonomi, sosial dan politik serta masyarakat tradisional dan pada akhirnya memperkenalkan sebuah tatanan sistem tata kelola sebuah kota yang baru. 
Pendekatan secara global pada beberapa tahun belakangan ini telah menjadi langkah yang membuat sebuah kota mengalami perubahan menjadi smart city. Pada saat ini, masyarakat menjadi maju dalam hal informasi secara cepat dan mempunyai kemampuan dalam produksi dan pertukaran informasi (Zeynali Azim A \& et al, 2012). Dalam sebuah smart city, semua warga membutuhkan pelayanan yang disediakan oleh sebuah jaringan informasi (information networks). Dengan demikian tidak lagi diperlukan pergerakan warga secara fisik untuk mengakses layanan pemerintah dan lembaga swasta.

Konsep smart City merupakan konsep yang telah melalui penyempurnaanpenyempurnaan dari konsep yang telah terlebih dahulu berkembang dengan menambal kekurangan-kekurangan yang ada dan mempertimbangkan aspek-aspek yang mungkin belum ada pada konsep-konsep berbasis Teknologi Informasi dan Komunikasi (TIK) yang telah muncul sebelumnya. Konsep ini pada akhirnya tidak hanya mendasarkan pembangunan dan pengelolaan kota dalam dimensi teknologi, namun juga mencakup dimensi manusia dan dimensi institusional (Nam \& Pardo, 2011).

Pada sebuah smart city, terdapat perubahan dari kantor secara fisik yang digantikan oleh kantor digital dan organisasi dan perangkat daerah seperti angkutan umum, kantor pengairan dll, menyediakan sebagian besar layanan kepada pelanggan menggunakan fasilitas yang disediakan oleh TIK. Proyek seperti ini dalam pelaksanaannya memerlukan sebuah perencanaan yang komprehensif dan desain dan kerangka (framework) yang berbeda.

Situasi diatas menggarisbawahi tiga pesan utama: pertama, kebutuhan untuk menjadikan masyarakat terorganisir dan terkelola sekaligus melahirkan suatu proses reformasi global; kedua, pengidentifikasian kota sebagai sebuah lahan subur tempat reorganisasi berasal; ketiga, harapan ditempatkan pada teknologi informasi dan komunikasi sebagai pusat perubahan. Kedua pertanyaan dibawah ini dianggap dapat mewakili permasalahan diatas:

1. Bagaimana transisi perubahan yang harus dialami sebuah kota agar dapat dikelola?

2. Apa peranan TIK dalam proses pengelolaannya?

Bahasan selanjutnya adalah sebagai berikut, bagian dua membahas tinjauan pustaka yang akan memaparkan konsep-konsep penting mengenai topik bahasan, bagian ketiga berisi kerangka kerja yang diusulkan untuk menggambarkan peran dari TIK dalam pengelolaan smart cities, bagian keempat memperkenalkan sebuah paradigma tata kelola yang diperoleh dari teknologi informasi dan komunikasi.

\section{Landasan Teori}

\subsection{Teknologi Informasi dan Komunikasi}

Teknologi adalah pengembangan dan aplikasi dari alat, mesin, material dan proses yang menolong manusia menyelesaikan masalahnya. Informasi adalah hasil pemrosesan, manipulasi dan pengorganisasian/penataan dari 
sekelompok data yang mempunyai nilai pengetahuan (knowledge) bagi penggunanya.

\subsection{Smart city}

Definisi dari smart city masih merupakan konsep yang tidak jelas yang dipakai tidak secara konsisten dalam literatur (Tranos and Gertner, 2012). Istilah serupa yang sering digunakan adalah intelligent cities, virtual cities, knowledge-based cities, digital cities atau information cities telah menambah konsep mengenai smart city. (Aurigi, 2005; Schaffers et al , 2011).

Sebuah smart city sering didefinisikan dari hasil yang diperolehnya dan konsep smart diperoleh dari kota tersebut lebih efisien, berkelanjutan, keadilan yang merata, dan kelayakan hunian (Alawadhi et al., 2012). Tetapi bagaimana tujuan ini dapat dicapai. Dalam penelitian mengenai smart cities yang telah dianalisa, ditemukan adanya hubungan antara hal yang menyambungkan antara teknis (smart technologies), sumberdaya manusia (smart people), dan tata kelola (smart collaborations). Dalam hal teknik, penekanan kemungkinan terhadap teknologi baru menawarkan untuk memperkuat sistem perkotaan. Teknologi berkisar dari teknologi energi canggih (smart grid) untuk mengangkut sistem dan sistem pengaturan lalu lintas. Aspek yang berulang untuk definisi smart cities adalah penggunaan TIK dalam beberapa cara (Walravens, 2012; Hoon Lee et al, 2013.).

Washburn et al. (2010:2) mendefinisikan sebuah smart city sebagai 'penggunaan teknologi smart computing untuk membuat komponenkomponen penting infrastruktur dan layanan kota - yang meliputi administrasi kota, pendidikan, kesehatan, keselamatan publik, real estate, transportasi, dan utilities- -lebih cerdas, saling berhubungan, dan efisien '. Bahkan, konsep smart city dapat dilihat sebagai pengakuan semakin pentingnya teknologi digital untuk posisi kompetitif dan masa depan yang berkelanjutan (Schuurman et al., 2012).

\subsection{Smart Technology}

Aurigi (2005) berpendapat bahwa, meskipun ada banyak perspektif yang berbeda mengenai smart city, gagasan bahwa TIK merupakan pusat tata kelola kota masa depan merupakan inti dari semua perspektif. Komninos (2002), Hollands (2008) dan Caragliu dkk. (2009, 2011) setuju bahwa peran TIK adalah karakteristik smart city yang utama. Ini tidak berarti bahwa alur teknologi ini dalam literatur tidak mengakui isu-isu sosial. Semua penulis ini menyoroti pentingnya pembangunan perkotaan yang dipimpin oleh pebisnis, termasuknya agenda sosial, peran industri kreatif dalam pertumbuhan perkotaan, pentingnya modal sosial dalam pembangunan perkotaan dan keberlanjutan perkotaan.

Fitur utama dari pendekatan ini adalah teknologi yang membentuk titik awal untuk memikirkan kembali semua masalah lainnya (Walravens, 2012; Hoon Lee et al, 2013.). Sebuah perspektif sederhana dari konsep 
smart city ini adalah bahwa kota pintar mengacu pada taman bisnis atau kabupaten mana banyak perusahaan dalam bidang TI atau teknologi baru lainnya berada (Giffinger et al. 2007, Fusco Girard et al. 2009, Caragliu et al. 2009).

Sumber daya manusia pada konsep smart city tidak mengabaikan teknologi, tetapi berfokus pada smart people sebagai pusat operasi smart city. Smart city dapat dianggap sebagai daerah metropolitan dengan sebagian besar dari populasi orang dewasa memiliki gelar sarjana (Shapiro, 2006). Ukuran wilayah smart city sering kali kecil dan metropolitan menengah yang mengandung masyarakat unggulan dari perguruan tinggi negeri dan telah bereksperimen terhadap pertumbuhan kota yang semakin dalam tahun terakhir (Winters, 2011). Konsep Smart city di alur ini terutama dibangun pada karakteristik masyarakat yang cerdas, dalam hal mereka berkelas dalam pendidikan (smart people).

\subsection{Smart People}

Para penulis ini telah menggunakan konsep smart city dimana berarti pengertian sebuah kota di mana sumber daya manusia, dan terutama, tingkat pendidikan, merupakan pendorong utama pertumbuhan perkotaan (Shapiro, 2006;. Lombardi et al, 2012;. Hoon Lee et al, 2013). Penelitian sebelumnya telah mencoba untuk menjelaskan mengapa smart city dapat tumbuh. Beberapa akademisi menunjukkan bahwa perpindahan dari para pekerja ke kota dengan tingkat sumber daya manusia yang lebih tinggi karena kota-kota merupakan daerah yang lebih produktif dan upah yang diberikan biasanya lebih tinggi (Rauch, 1993; Glaeser dan Saiz, 2004; Moretti, 2004a).

Hal lainnya menunjukkan bahwa penduduk yang berpendidikan dapat meningkatkan kualitas hidup di kota dan masyarakat berduyun-duyun ke kota untuk kualitas hidup yang lebih tinggi (Shapiro, 2006). Hal yang lain menunjukkan bahwa pertumbuhan dari smart city dapat dijelaskan bahwa sebagian disebabkan karena siswa pindah untuk mengejar pendidikan tinggi dan kemudian tinggal di kota setelah mereka selesai dengan pendidikan mereka (Winters, 2011).

\subsection{Smart collaboration}

Kolaborasi menyoroti interaksi antara teknologi dan struktur sosial. Dalam pendekatan ini, smart city didefinisikan berdekatan dengan konsep serupa tapi berbeda seperti kota digital, intelligent cities atau ubiquitous cities. Dikatakan bahwa konsep smart city sebenarnya adalah evolusi yang berpusat pada pengguna lebih dari konsep kota yang lainnya yang lebih determinan terhadap teknologi (Schuurman et al., 2012).

Inovasi dan data terbuka untuk dilihat publik merupakan elemen kunci dari smart city (Schaffers et al., 2011). Ide kolaborasi menjadi lebih sentral untuk pendekatan ini dan fokus pada pengembangan interaksi yang 
produktif antara sistem teknis dan jaringan pelaku perkotaan (Nam \& Pardo, 2011;. Chourabi et al, 2012).

\section{Smart city initiatives}

Satu faktor komprehensif yang penting untuk dapat memahami smart city initiatives dan proyek-proyek didalamnya adalah bagaimana faktor-faktor ini, membawa ke smart city framework, dan dapat digunakan untuk mempelajari dan menentukan faktor keberhasilan smart city initiatives dan proyek-proyek didalamnya. Selain sustainability dan livability, kerangka kerja ini membahas beberapa faktor internal dan eksternal yang mempengaruhi desain, implementasi, dan penggunaan smart city initiatives. Tujuannya adalah tidak hanya untuk menghasilkan satu set komponen untuk menilai smart city, tetapi untuk menciptakan kerangka kerja yang dapat digunakan untuk mengkarakterisasi bagaimana membayangkan sebuah kota dan desain smart initiatives, dan memajukan visi ini dengan menerapkan layanan bersama, dan menavigasi tantangan yang muncul. Delapan kelompok faktor tersebut termasuk (1) manajemen dan organisasi, (2), (3) tata kelola, (4) kebijakan, (5) orang dan masyarakat, (6) ekonomi, (7) membangun infrastruktur, dan (8) lingkungan alam.

\subsection{Manajemen dan organisasi}

Gil-Garcia dan Pardo (2005) menyarankan daftar faktor-faktor keberhasilan dan tantangan untuk inisiatif e-government (lihat Tabel 1). Smart city initiative mungkin berbeda dari inisiatif e-government dalam konteks umum dan dalam beberapa karakteristik dari proyek-proyek tertentu, tetapi ada banyak kesamaan antara dua jenis inisiatif karena kebanyakan smart city initiative juga didorong oleh pemerintah dan dimanfaatkan dengan penggunaan TIK secara intensif untuk lebih melayani warga.

Tabel 1. Managerial and organizational challenges and strategies

\begin{tabular}{|c|c|}
\hline Challenges & Strategies \\
\hline $\begin{array}{l}\text { - Project size } \\
\text { - Manager's attitudes and } \\
\text { Behavior }\end{array}$ & $\begin{array}{l}\text { - Project team skills and expertise } \\
\text { - Well skilled and respected IT leader } \\
\text { (technical and social skills) }\end{array}$ \\
\hline $\begin{array}{l}\text { - Users or organizational } \\
\text { diversity }\end{array}$ & - Clear and realistic goals \\
\hline $\begin{array}{l}\text { - Lack of alignment of } \\
\text { organizational goals and } \\
\text { project }\end{array}$ & $\begin{array}{l}\text { - Identification of relevant } \\
\text { stakeholeders }\end{array}$ \\
\hline - Multiple or conflicting goals & - End-user involvement \\
\hline - Resistance to change & - Planning \\
\hline
\end{tabular}


- Turf and conflict

- Clear milestones and measurable deliverables

- Good communication

- Previous bussiness process improvement

- Adequate training

- Adequate and innovative funding

- Current or best practices review

Sumber : Gil-Garcia dan Pardo (2005)

\subsection{Teknologi}

TIK merupakan pendorong utama dari smart city initiatives (Hollands, R.G., 2008). Integrasi TIK dengan proyek-proyek pembangunan dapat mengubah lanskap perkotaan sebuah kota (Vasseur, J., 2010). dan menawarkan sejumlah potensi peluang (Odendaal, N., 2003). TIK dapat meningkatkan pengelolaan dan fungsi kota. Meskipun keuntungan dan manfaat TIK dicanangkan untuk digunakan dalam kota, dampaknya masih belum jelas.

TIK dapat meningkatkan kualitas hidup bagi warga negara, tetapi juga dapat meningkatkan ketidaksetaraan dan mempromosikan kesenjangan digital. Dengan demikian, pengelola kota harus mempertimbangkan faktor-faktor tertentu ketika mengimplementasikan TIK dengan memperhatikan ketersediaan sumber daya, kapasitas, kesediaan kelembagaan dan juga berkaitan dengan kesenjangan, kesenjangan digital dan perubahan budaya dan kebiasaan. Ebrahim dan Irani (2005) telah menjelaskan beberapa tantangan menggunakan teknologi yang di smart city. (Lihat Tabel 2).

Tabel 2. Tantangan Teknologi

\begin{tabular}{ll}
\hline \multicolumn{1}{c}{ Dimension } & \multicolumn{1}{c}{ Challenges } \\
\hline IT Skills & IT training programs \\
& $\begin{array}{l}\text { Lack employees with integration skill and } \\
\text { culture }\end{array}$ \\
\hline Organizational & Lack of cross-sectoral cooperation \\
& Lack of inter-departemental coordination
\end{tabular}




\section{Unclear vision of IT management Politics}

Culture issues

Sumber : Ebrahim dan Irani (2005)

\subsection{Tata Kelola}

Secara umum, (publik) governance telah didefinisikan "sebagai rezim hukum, aturan administrasi, putusan pengadilan, dan praktik yang membatasi, ketetapan, dan kegiatan pemerintah yang memungkinkan, di mana aktivitas tersebut secara luas didefinisikan sebagai produksi dan pengiriman didukung barang dan jasa publik. "(Lynn, L. E., et al., 2000:235). Governance melibatkan pelaksanaan proses dengan para pendukung yang bertukar informasi menurut aturan dan standar dalam rangka mencapai tujuan dan sasaran. Scholl et al. (2009) mempelajari tantangan kunci proyek e-government, dan menemukan bahwa hubungan stakeholder 'adalah salah satu faktor penting untuk menentukan keberhasilan atau kegagalan proyek-proyek tersebut. "Hubungan Stakeholder" mengacu pada empat isu utama: kemampuan untuk bekerja sama di antara para pemangku kepentingan, dukungan kepemimpinan, struktur aliansi dan bekerja di bawah yurisdiksi yang berbeda.

Sedikit literatur tentang smart city membahas masalah-masalah yang berkaitan dengan pemerintahan. Menurut Mooij (2003), kehadiran kepemimpinan adalah penting untuk governance yang baik. Dengan cara yang sama, Lam (2005) menekankan pada adanya "juara (champion)" yang berkolaborasi dengan semua pemangku kepentingan sebagai faktor penting untuk pemerintahan yang baik. Smart governance digambarkan sebagai karakteristik penting dari sebuah smart city yang didasarkan pada partisipasi warga (Giffinger, R., 2007) dan swasta / kemitraan publik (Odendaal, N., 2003). Menurut Johnston dan Hanssen et al, smart governance tergantung pada pelaksanaan infrastruktur smart governance yang harus bertanggung jawab, responsif dan transparan (Mooij, J. (2003). Infrastruktur ini membantu memungkinkan kolaborasi, pertukaran data, integrasi layanan dan komunikasi (Odendaal, N., 2003). Tabel 3 merangkum faktor governance yang relevan ditemukan dari literatur.

\section{Tabel 3. Governance}

\begin{tabular}{l}
\hline \multicolumn{1}{c}{ Factors } \\
\hline Collaboration \\
Leadership and Champion \\
Participation and partnership \\
Communication \\
Data Exchange \\
Service and Application
\end{tabular}


integration

Accountability

Transparency

\subsection{Kontext Kebijakan}

Konteks kebijakan sangat penting untuk digunakan dalam memahami penggunaan sistem informasi dengan cara yang tepat. Oleh karena itu, pemerintah yang inovatif menekankan perubahan kebijakan, karena pemerintah tidak bisa berinovasi tanpa arahan normatif yang dibahas dalam kebijakan (Eger, J. M., \& Maggipinto, A., 2010). Sedangkan inovasi dalam teknologi untuk smart city dapat relatif dengan mudah diamati dan secara luas disepakati, perubahan berikutnya dalam konteks kebijakan yang lebih ambigu (Hartley, J., 2005). Konteks kebijakan merupakan ciri masalah pemerintah perkotaan dan masalah non-teknis yang menciptakan kondisi yang memungkinkan bagi pembangunan perkotaan (Yigitcanlar, T., \& Velibeyoglu, K., 2008).

Gil-García dan Pardo mempelajari faktor-faktor keberhasilan egovernment yaitu hukum, peraturan, kelembagaan dan tantangan lingkungan terhadap inisiatif e-government. Smart city initiatives menghadapi tantangan serupa yang mempengaruhi konteks kebijakan. Organisasi pemerintah dibuat dan dioperasikan berdasarkan aturan formal tertentu atau aturan kelompok. Dalam membuat segala jenis keputusan dalam proyek-proyek TI, manajer umum perlu mempertimbangkan sejumlah besar batasan hukum dan peraturan (Dawes, S. S., \& Pardo, T. A., 2002).

\subsection{People and communities}

Masalah people and communities sebagai bagian dari smart city sangat penting, dan secara tradisional telah diabaikan dengen mengorbankan pemahaman lebih mementingkan aspek teknologi dan kebijakan dari sebuah smart city. Proyek dari smart city berdampak pada kualitas hidup warga dan bertujuan untuk mendorong warga lebih banyak diberikan kemudahan memperoleh informasi, berpendidikan, dan partisipatif dalam masyarakat.

Selain itu, smart city initiatives memungkinkan warga kota untuk berpartisipasi dalam tata kelola dan manajemen kota dan menjadi pengguna aktif. Jika mereka merupakan pemain kunci mereka mungkin memiliki kesempatan untuk terlibat dengan inisiatif sehingga dapat mempengaruhi upaya untuk smart city menjadi sukses atau gagal. Tabel 4 berisi daftar faktor terkait dengan smart city dan people and communities seperti yang ditemukan dalam literatur.

Tabel 4. Tabel dari people and communities 


\begin{tabular}{l}
\hline \multicolumn{1}{c}{ Factor } \\
\hline Digital divide(s) \\
Information and community gatekeepers \\
Participation and partnership \\
Communication \\
Education \\
Quality of life \\
Accessibility \\
\hline
\end{tabular}

\subsection{Economy}

Ekonomi adalah pendorong utama dari smart city initiatives, dan sebuah kota dengan daya saing ekonomi tingkat tinggi diperkirakan memiliki salah satu sifat dari smart city. Juga, salah satu indikator kunci untuk mengukur kompetisi kota berkembang adalah kapasitas kota sebagai mesin penggerak ekonomi (Giffinger, R., Kramar, H., \& Haindl, G., 2008). Giffinger et al (2007) menyarankan smart city framework yang terdiri dari enam komponen utama (smart economy, smart people, smart government, smart mobility, smart environment, and smart living). Definisi dari smart economy meliputi faktor seluruh daya saing inovasi ekonomi, kewirausahaan, merek dagang, produktivitas dan fleksibilitas tenaga kerja pasar serta integrasi di pasar nasional dan global.

\subsection{Built Infrastructure}

Ketersediaan dan kualitas dari infrastruktur TIK merupakan hal penting bagi sebuah smart city (Giffinger, R.; 2007). Smart object network memainkan peran penting dalam membuat smart city menjadi kenyataan (Vasseur, J., 2010). Infrastruktur TIK termasuk wireless infrastructure (fiber optic channels, Wi-Fi networks, wireless hotspots, kiosks, serviceoriented information systems (Anthopoulos, L., \& Fitsilis, P., 2010).

Pelaksanaan infrastruktur TIK merupakan dasar untuk pengembangan smart city dan tergantung pada beberapa faktor yang berhubungan dengan availability dan performance. Ebrahim dan Irani (2005) menyajikan satu set faktor yang berhubungan dengan pelaksanaan TIK. Tabel 5 menyajikan satu set tantangan TI yang dikelompokkan dalam tiga dimensi; Infrastruktur TI, keamanan dan privasi, dan biaya operasional.

Tabel 5. Factors of built infrastructure

\begin{tabular}{cc}
\hline Dimension & \multicolumn{1}{c}{ Challenges } \\
\hline & $\bullet$ Lack of integration across government systems \\
& $\bullet \quad$ Exixting internal systems have restrictions \\
IT infrastructure & - regarding their integrating capabilities \\
& $\bullet$ Availability and compability of software, systems \\
& and applications \\
\hline
\end{tabular}


- Threats from hackers and intruders

- Theats from viruses, worms and Trojans

Security and

privacy

- Privacy of personal data

- High cost of security applications and solutions

- accessibility

- High cost of IT professionals and consultancies

- High cost of IT

Operational cost

- Cost of installation, operation and maintenance of information systems

- Cost of training

\subsection{Natural environment}

Inti dengan konsep smart city adalah penggunaan teknologi untuk meningkatkan

sustainability dan untuk mengelola sumber daya alam (Natural Resources Defense Council). Yang menarik adalah perlindungan sumber daya alam dan infrastruktur terkait (Hall, R. E., 2000). seperti saluran air dan selokan dan ruang hijau seperti taman. Bersama-sama faktor-faktor ini berdampak pada sustainability dan livability sebuah kota, yang merupakan hal yang harus dipertimbangkan ketika memeriksa smart city initiative.

\section{Smart city framework}

Framework yang integratif dipergunakan untuk menjelaskan hubungan dan pengaruh antara faktor-faktor pendukung dan smart city initiatives. Masingmasing faktor sangat penting untuk dipertimbangkan dalam menilai level smart city dan ketika memeriksa smart city initiative. Faktor yang memberikan dasar untuk membandingkan bagaimana kota ini mewujudkan smart initiative, menerapkan layanan bersama, dan berbagai tantangan terkait. Faktor ini juga disajikan sebagai alat untuk mendukung pemahaman tentang keberhasilan yang relatif dari smart city initiative yang berbeda dilaksanakan dalam konteks yang berbeda dan untuk tujuan yang berbeda. Demikian pula, framework ini bisa membantu untuk mengurai dampak sebenarnya pada berbagai jenis variabel (organisasi, teknis, kontekstual) pada keberhasilan smart city initiatives 


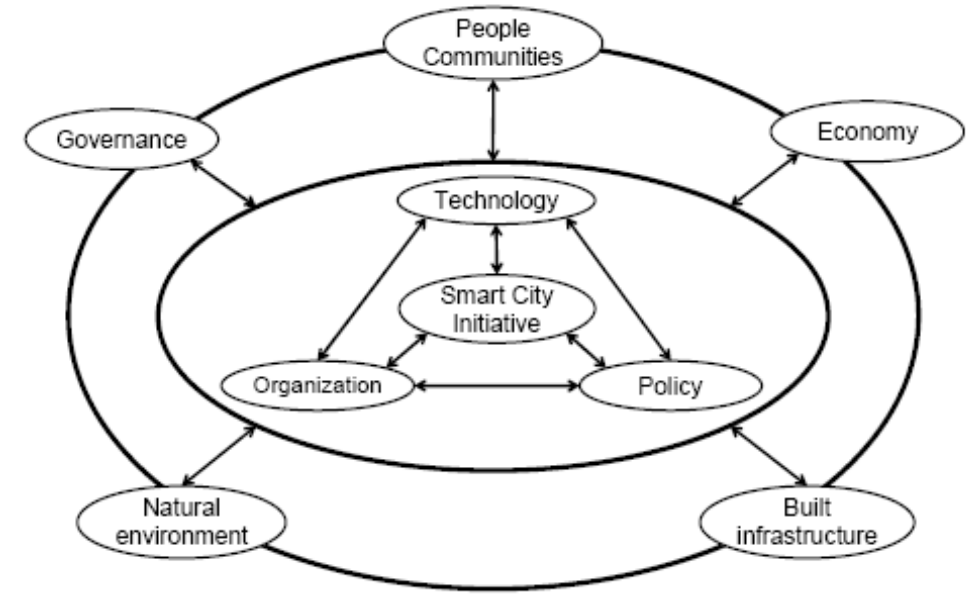

Gambar 1. Smart city initiatives framework

Diharapkan bahwa sementara semua faktor memiliki dampak dua arah dalam smart city initiatives (masing-masing mungkin dipengaruhi oleh dan mempengaruhi faktor-faktor lain), di waktu yang berbeda dan dalam konteks yang berbeda, beberapa faktor lebih berpengaruh daripada yang lain. Dalam rangka untuk mencerminkan tingkat perbedaan dari dampak, faktor dalam framework yang diusulkan terwakili dalam dua tingkat pengaruh yang berbeda. Faktor luar (governance, people and community, lingkungan alam, infrastruktur, dan ekonomi) yang dalam beberapa cara disaring atau dipengaruhi lebih dari inner factor (teknologi, manajemen, dan kebijakan) sebelum mempengaruhi keberhasilan smart city initiative. Hal ini penting untuk kedua efek langsung dan tidak langsung dari faktor luar. Teknologi mungkin dianggap sebagai meta-faktor dalam smart city initiative, karena sangat mempengaruhi masing-masing dari tujuh faktor lainnya. Karena pada kenyataannya banyak smart city initiative yang secara intensif menggunakan teknologi, itu bisa dilihat sebagai faktor yang dalam beberapa cara mempengaruhi semua faktor sukses lainnya dalam framework ini.

\section{Daftar Pustaka :}

[1] Alawadhi, S.; Aldama-Nalda, A.; Chourabi, H.; Gil-Garcia, J. R.; Leung, S.; Mellouli, S.; Nam, T.; Pardo, T. A.; Scholl, H. J. and Walker S. (2012). Building Understanding of Smart City Initiatives. In: Hans J. Scholl, Marijn Janssen, Maria A.Wimmer, Carl Erik Moe, Leif Skiftenes Flak (Eds.): EGOV 2012. Lecture Notes in Computer Science 7443, pp. 40-53.

[2] Al-Hader, M., \& Rodzi, A. (2009). The smart city infrastructure development \& monitoring. Theoretical and Empirical Researches in Urban Management, 4(2), 87-94. 
[3] Anthopoulos, L., \& Fitsilis, P. (2010). From digital to ubiquitous cities: Defining a common architecture for urban development. In Proceedings of the $6^{\text {th }}$ International Conference on Intelligent Environments, Kuala Lumpur, Malaysia, July 19-21.

[4] Caragliu, A., Del Bo, C. and Nijkamp, P. (2009). Smart Cities in Europe. Proceedings to the 3rd Central European Conference on Regional Science. Košice, Slovak Republic.

[5] Caragliu, A., Del Bo, C. and Nijkamp, P. (2011). Smart Cities in Europe. Journal of Urban Technology, 18(2), 65-82.

[6] Chourabi, H.; Nam, T.; Walker, S.; Gil-Garcia, J. R.; Mellouli, S.; Nahon, K.; Pardo, T. A. and Scholl, H. J. (2012). Understanding Smart City Initiatives: An Integrative and 11 Comprehensive Theoretical Framework. In: Proceedings of the 45th Hawaii International Conference on System Sciences, pp. 2289-2297

[7] Dawes, S. S., \& Pardo, T. A. (2002). Building collaborative digital government systems. In McIver, W. J., \& Elmagarmid, A. K. (Eds.), Advances in Digital Government: Technology, Human Factors, and Policy. Norwell, MA: Kluwer Academic Publishers.

[8] Ebrahim, Z., \& Irani, Z. (2005). E-government adoption: Architecture and barriers. Business Process Management Journal, 11(5), 589-611.

[9] Eger, J. M., \& Maggipinto, A. (2010). Technology as a tool of transformation: e-Cities and the rule of law. In A. D'Atri \& Saccà, D. (Eds.), Information Systems: People, Organizations, Institutions, and Technologies (pp. 23-30). Berlin/Heidelberg, Germany: Physica-Verlag.

[10] Fusco Girad, L.; Lombardi, P. and Nijkamp, P. (2009). Creative urban design and development. International Journal of Services Technology and Management, 13 (2-3), 111-115.

[11] Giffinger, R.; Fertner, C.; Kramar, H.; Meijers, E. and Pichler-Milanović, N. (2007). Smart Cities: Ranking of European medium-sized cities. Vienna. Available http://www.smartcities.eu/download/smart cities_final_report.pdf.

[12] Giffinger, R., Kramar, H., \& Haindl, G. (2008). The role of rankings in growing city competition. In Proceedings of the 11th European Urban Research Association (EURA) Conference, Milan, Italy, October 9-11, http://publik.tuwien.ac.at/files/PubDat 167218.pdf.

[13] Gil-García, J. R., \& Pardo, T. A. (2005). E-government success factors: Mapping practical tools to theoretical foundations. Government Information Quarterly, 22(2), 187-216. 
[14] Hall, R. E. (2000). The vision of a smart city. In Proceedings of the 2nd International Life Extension Technology Workshop, Paris, France, September 28, Tersedia di

[15] http://www.osti.gov/bridge/servlets/purl/773961oyxp82/webviewable/773961.pdf.

[16] Hartley, J. (2005). Innovation in governance and public services: Past and present. Public Money \& Management, 25(1), 27-34.

[17] Hollands, R.G. (2008). Will the real smart city please stand up. City, 12(3), 303-320.

[18] Hoon Lee, J. H.; Phaal, R. and Lee, S-H. (2013). An integrated servicedevice-technology roadmap for smart city development. Technological Forecasting \& Social Change, 80 (2), 286-306.

[19] Johnston, E. W., \& Hansen, D. L. (forthcoming). Design lessons for smart governance infrastructures. In Ink, D., Balutis, A., \& Buss, T. F. (Eds.), American Governance 3.0: Rebooting the Public Square? National Academy of Public Administration. http://icma.org/en/icma/knowledge_network/documents/kn/document/30154 $\underline{0 / \text { design lessons for smart governance infrastructures. }}$.

[20] Lam, W. (2005). Barriers to e-government integration. The journal of Enterprise Information Management, 18(5), 511-530.

[21] Lynn, L. E., Heinrich, C. J., \& Hill, C. J. (2000). Studying governance and public management: Challenges and prospects. Journal of Public Administration Research and Theory, 10(2), 233-262.

[22] Lombardi, P.; Cooper, I.; Paskaleva, K. and Deakin, M. (2009). The challenge of designing usercentric e-services: european dimensions. In: C. Reddick, ed. Strategies for local egovernment adoption and implementation: comparative studies. Hershey, PA: Idea Group Publishing.

[23] Nam, Taewoo; \& Pardo, Theresa A. (2011). "Conceptualizing Smart City with Dimensions of Technology, People, and Institutions", The Proceedings of the 12th Annual International Conference on Digital Government Research.

[24] Natural Resources Defense Council. What are smarter cities?, Tersedia di http://smartercities.nrdc.org/about.

[25] Odendaal, N. (2003). Information and communication technology and local governance: Understanding the difference between cities in developed and emerging economies. Computers, Environment and Urban Systems, 27(6), 585-607.

[26] Shapiro, J. M. (2006). Smart Cities: Quality of Life, Productivity, and the Growth Effects of Human Capital. Review of Economics and Statistics, 88, 324-335. 
[27] Schaffers, H.; Komninos, N.; Pallot, M.; Trousse, B.; Nilsson, M. and Oliveira, A. (2011). Smart Cities and the Future Internet: Towards Cooperation Frameworks for Open Innovation. In: J. Domingue et al. (Eds.): Future Internet Assembly, LNCS 6656, pp. 431-446.

[28] Scholl, H. J., Barzilai-Nahon, K., Ahn, J-H., Olga, P., \& Barbara, R. (2009). E-commerce and e-government: How do they compare? What can they learn from each other?. Proceedings of the 42nd Hawaiian International Conference on System Sciences (HICSS 2009), Koloa, Hawaii, January 4-7.

[29] Schuurman, D. ; Baccarne, B. ; De Marez, L. and Mechant, P. (2012). Smart Ideas for Smart Cities: Investigating Crowdsourcing for Generating and Selecting Ideas for ICT Innovation in a City Context. Journal of Theoretical and Applied Electronic Commerce Research, 7 (3), 49-62.

[30] Tranos, E. and Gertner, D. (2012). Smart networked cities?. Innovation: The European Journal of Social Science Research, 25 (2), 175-190.

[31] Vasseur, J. (2010). Smart cities and urban networks. In Vasseur, J. \& Dunkels, A. (Eds.), Interconnecting Smart Objects with IP: The Next Internet (pp. 360-377). Burlington, MA: Morgan Kaufmann.

[32] Walravens, N. (2012). Mobile Business and the Smart City: Developing a Business Model Framework to Include Public Design Parameters for Mobile City Services. Journal of Theoretical and Applied Electronic Commerce Research, 7 (3), 121-135.

[33] Washburn, D.; Sindhu, U.; Balaouras, S.; Dines, R. A.; Hayes, N. M. and Nelson, L. E. (2010). Helping CIOs Understand "Smart City" Initiatives: Defining the Smart City, its Drivers, and the Role of the CIO. Cambridge, MA: Forrester Research, Inc.

[34] Winters, J. V. (2011). Why are smart cities growing? Who moves and who stays. Journal of Regional Science, 51(2), 253-270.

[35] Yigitcanlar, T., \& Velibeyoglu, K. (2008). Knowledgebased urban development: The local economic development path of Brisbane, Australia. Local Economy, 23(3), 195-207.

[36] Zeynali Azim A \& et al, "Electronic city: A City of Today and Tomorrow", J. Basic. Appl. Sci. Res., 2(7), 6615-6621, (2012). 